\title{
Hard line take on public health gives Brazil soft political power
}

With its booming economy and surging population, Brazil is expected to emerge as one of the major global powerhouses of the $21 \mathrm{st}$ century. But the country's growing influence on the world stage is driven by more than just raw economic and demographic might. Brazil has been particularly adept among so-called BRIC (Brazil, Russia, India and China) nations at using a gently persuasive form of 'soft power' diplomacy-and the country is using public health issues in particular to leverage longterm economic and political gain.

Brazil's HIV/AIDS policy is probably the best example of what some experts have dubbed the country's 'health industrial complex'. In 1990, when more than 10,000 new AIDS cases were reported in the country, the World Bank famously predicted that Brazil would have 1.2 million infections by 2000 . But thanks to universal provision of antiretroviral drugs, starting in 1996, and government social programs aimed at encouraging condom use and needle exchange, the number of people now living with HIV in Brazil sits at around

What's more, a whole floor of the new center will be devoted to so-called 'flexible laboratories', where government scientists will work alongside collaborators from the private sector. For now, however, the entire 150,000-square-foot building_including the spiral staircase leading to the main entrance and the curved, aerofoil-shaped roof-remains shrouded in scaffolding.

Some of the first projects likely to benefit from the new facility are partnerships between Fiocruz and foreign drug companies, including Britain's GlaxoSmithKline and the US's Genzyme, to develop treatments for a range neglected diseases such as dengue fever. In addition, CDTS scientists will focus on cancer, diabetes, hypertension and other noncommunicable diseases that represent a source of growing concern for public health in Brazil. "We are undergoing an epidemiological transition, and Fiocruz is reorienting its actions to act in both fronts," Morel says.

According to Reinaldo Guimarães, an independent consultant in public health management and a former executive of the Ministry of Health, this new center should help Brazilian biomedical researchers cross the so-called 'valley of death' of drug
730,000 , with a prevalence rate on par with that of the US.

Buoyed by its successful track record, Brazil has used its international reputation and expertise to help several sub-Saharan African countries confront their ongoing HIV epidemics. Over the past decade, for example, Brazil has sent delegates to Mozambique, Nigeria and Angola to build up pharmaceutical plants and then hosted workshops back in the capital city, Brasilia, for African health officials to gain technical training for analytical techniques and strategies for drug production.

"The ministry of foreign affairs has always wanted to market Brazil's success with AIDS," says Eduardo Gómez, a political scientist at Rutgers University in Camden, New Jersey who has studied the geopolitical incentives that led Brazilian officials to help Africa combat the disease (Geo. Public Poly. Rev. 37, $15,2009)$. "Brazil's not so focused on money, like the US, but on knowledge about how to build sustainable pharmaceutical companies, for example. Equally, it doesn't ask for access

development. "But," he notes, "it will not solve this problem alone. Brazil needs other centers like this if we want to foster translational science."

Although no other Brazilian institution has built anything as ambitious - or as architecturally distinct-as CDTS, many academic centers throughout the country are improving their laboratories for translational research. For example, in 2009 the René Rachou Research Center, a Fiocruz unit in Belo Horizonte, inaugurated its Excellence Center in Bioinformatics, which is aimed at attracting private companies to use its facilities for computationally driven drug development. In a similar strategy, the University of São Paulo's Institute of Biomedical Sciences (ICB) is about to launch a new core facility with the latest proteomics and genomics technologies. "Our purpose," says ICB director Rui Curi, "is to provide access to huge expensive facilities that could not be afforded by individual projects from our university scientists and from other institutions, including private partners."

Now the research community is waiting to see whether once they build it, the drug discoveries will come.

Bernardo Esteves to oil [in return], like China, or try to redeem itself in some way like the US. It is trying to increase its standing."

Brazil has similarly demonstrated global leadership when it comes to tobacco control, notes Kelley Lee, a health policy researcher at the London School of Hygiene and Tropical Medicine. Although the country is one of the biggest producers and exporters of tobacco in the world, Brazil established a strict national tobacco control program that led to a $35 \%$ drop in the adult smoking rate between the start of the effort in 1989 and 2003. As chronicled by Lee and her colleagues, Brazilian officials then promoted these advances and used their diplomatic channels to help build international consensus for the World Health Organization's Framework Convention of Tobacco Control, signed in 2003 (PLoS Med. 7, e1000232, 2010).

As a result, Brazilian diplomats have been appointed to a number of key positions within the World Health Organization (WHO) and the UN. Most recently, the country was also chosen to host the new South American Institute of Government in Health (ISAGS), which opened its doors in July in Rio de Janeiro as a place to facilitate the sharing of skills and ideas on public health between Latin American countries.

But tobacco control and HIV are not the only arenas for Brazil's soft but powerful diplomatic approach. "Whenever there are formal negotiations on global health issues"for example, the WHO's April 2011 agreement on sharing influenza-virus samples or last month's UN High-Level Meeting on NonCommunicable Diseases- "Brazil is an active participant," says Lee. "The country is certainly not a two-trick pony."

In unpublished work, Gómez has examined how Brazilian diplomats are capitalizing on the country's policies toward tuberculosis and obesity. And João Augusto de Castro Neves, a political consultant based in Washington, DC, points to Brazil's leadership of the UN peacekeeping mission in Haiti as a demonstration to larger powers that it can handle affairs in its neighborhood of Latin America.

"That will give it better credentials to become a permanent member of the UN Security Council," Castro Neves says. "Health is an area Brazil has a comparative advantage. It has a problem with military resources, some fiscal problems. But for the past 20 years Brazil has developed a lot of expertise in health." By lending others a hand, it seems, health diplomacy is slowly helping Brazil to help itself.

Anna Petherick 